\title{
Gene Expression of Type I and Type III Collagen by Mechanical Stretch in Anterior Cruciate Ligament Cells
}

\author{
Sung-Gon Kim ${ }^{*}$, Toshihiro Akaike², Tadashi Sasagawa², Yoriko Atomi ${ }^{3}$, and Hisashi Kurosawa1 \\ ${ }^{1}$ Department of Orthopaedic Surgery, Juntendo University, Tokyo, Japan, ${ }^{2}$ Department of Biomolecular Engi- \\ neering, Tokyo Institute of Technology, Yokohama, Japan, and ${ }^{3}$ Department of Life Sciences, Graduate School \\ of Arts and Sciences, The University of Tokyo, Tokyo, Japan
}

\begin{abstract}
Mechanical stretch affects the healing and remodeling process of the anterior cruciate ligament (ACL) after surgery in important ways. In this study, the effects of mechanical stress on gene expression of type I and III collagen by cultured human ACL cells and roles of transforming growth factor (TGF)- $\beta 1$ in the regulation of mechanical strain-induced gene expression were investigated. Uniaxial cyclic stretch was applied on ACL cells at $10 \mathrm{cycles} / \mathrm{min}$ with $10 \%$ length stretch for $24 \mathrm{~h}$. mRNA expression of the type I and type III collagen was increased by the cyclic stretch. TGF- $\beta 1$ protein in the cell culture supernatant was also increased by the stretch. In the presence of anti-TGF- $\beta 1$ antibody, stretch-induced increase in type I and type III mRNA expression was markedly ablated. The results suggest that the stretch-induced mRNA expression of the type I and type III collagen is mediated via an autocrine mechanism of TGF- $\beta 1$ released from ligament cells.
\end{abstract}

Key words: anterior cruciate ligament (ACL)/fibroblast/mechanical stretch/type I collagen/type III collagen/transforming growth factor (TGF)- $\beta 1$

Ligaments are dense bands of connective tissue that connect bones and mediate normal joint movement and stability. Ligaments contain rows of fibroblasts within parallel bundles of extracellular matrix composed mainly of type I collagen and a small proportion of type III (Amiel et al., 1984). The anterior cruciate ligament (ACL) of the knee has a very important role for the restraint to anterior displacement of the tibia. It has been estimated that the ligament typically bears peak loads of about $169 \mathrm{~N}$ during normal ambulation, with a three-fold increase to $400 \mathrm{~N}$ to $500 \mathrm{~N}$ during strenuous athletic activity (Bessette and Hunter, 1990). Moreover, the posterolateral bundle of the ACL is stretched in extension of the knee and the anteromedial bundles become taut in flexion (Girgis et al., 1975; Amis and Dawkins, 1991). Therefore, the ligament fibroblasts are repeatedly stretched in physiological activities. Stress deprivation alters the morphologic and biochemical characteristics of the ligament tissue. In immobilized rabbit knee, significant losses of

*To whom correspondence should be addressed: Department of Orthopaedic Surgery, Juntendo University, 2-1-1 Hongo, Bunkyo-ku, Tokyo, Japan.

Tel: +81-3-3813-3111, Fax: +81-3-3813-3428

E-mail: s-kim@med.juntendo.ac.jp

Abbreviations: ACL, anterior cruciate ligament; TGF- $\beta 1$, transforming growth factor; RT-PCR, reverse transcription-polymerase chain reaction; ELISA, enzyme-linked immunosorbent assay. collagen mass were observed after 12 weeks (Harwood and Amiel, 1992). Stress-deprived rabbit ligament fibroblasts decreased the synthesis of fibronectin and increased the expression of $\beta 1$ and $\alpha 5$ integrins (AbiEzzi et al., 1997). These results suggest the importance of maintaining normal stress on ligaments to prevent the degradation of extracellular matrix components.

Rupture of the ACL often necessitates graft surgery due to the poor potential for healing and subsequent functional instability, meniscus injury and osteoarthritis. Mechanical stretch plays important roles in the remodeling process of the tendon graft. The effect of graft tension on remodeling of the autograft in ligament reconstruction was investigated using an in situ freezing model (Tohyama and Yasuda, 1998). Transmission electron micrographs revealed that the number of small diameter fibrils decreased in the stressshielded tendons compared with non-stress-shielded ones.

Transforming growth factor (TGF)- $\beta 1$ is known to play an important role in the healing and remodeling process of connective tissue. Previous reports have shown the TGF- $\beta 1$ to enhance healing of incisional skin wounds (Miyazono and Heldin, 1992), and TGF- $\beta 1$ has been observed to be present in the early healing stage of the lacerated ligament and reconstructed ACL (Lee et al., 1998; Kuroda et al., 
2000). In vivo and in vitro studies show that exogenous TGF- $\beta 1$ is able to enhance collagen secretion by ligament fibroblasts (Murphy et al., 1994; DesRosiers et al., 1996; Marui et al., 1997).

Although ligament fibroblasts are uniaxially stretched during normal activity, the response of ligament fibroblasts following in vitro uniaxial stretch has not been reported. The purpose of this study was to investigate effects on mRNA expression of type I and III collagen in the ACL fibroblasts after the application of cyclic stretch in vitro, and roles of TGF- $\beta 1$ in the regulation of mechanical straininduced gene expression.

\section{Materials and Methods}

\section{Cell culture}

Isolation of human ACL fibroblasts was performed as described by Nagineni et al. (Nagineni et al., 1992) with a modification of the explant culture technique. The ACLs were obtained by undergoing total knee arthroplasty in osteoarthritis. This study received the approval of the ethics committee of our institution and all patients gave their informed consent. The ligament was washed repeatedly in calcium- and magnesium-free phosphate buffered saline (PBS) and the synovial sheath was carefully scraped off. The tissue was cut into small pieces and placed in culture dishes containing growth medium. Growth medium consisted of Dulbecco's modified Eagle medium (DMEM) (Gibco BRL, Grand Island, NY) supplemented with heat-inactivated $10 \%$ fetal bovine serum (FBS) (Sigma Chemical Co., St. Louis, MO), $10 \mathrm{mM} \mathrm{NaHCO}$, $10 \mathrm{mM}$ HEPES, $10 \mathrm{mM}$ nonessential amino acids, and antibiotics $(50 \mu \mathrm{g} /$ $\mathrm{ml}$ penicillin, $50 \mu \mathrm{g} / \mathrm{ml}$ streptomycin and $100 \mu \mathrm{g} / \mathrm{ml}$ neomycin). The culture dishes were incubated at $37^{\circ} \mathrm{C}$ in a humidified atmosphere of $5 \% \mathrm{CO}_{2}$ and $95 \%$ air. The explant pieces were removed when adequate cell outgrowth had been observed. After cells reached confluency, cells were detached by treating with PBS containing trypsin $(0.125 \%)$ and EDTA $(0.2 \%)$. The ligament fibroblasts between passage one and four were used.

\section{Mechanical stretch application}

A system applied for uniaxial cyclic stretch to cultured cells on a silicon membrane was developed (Fig. 1). ACL fibroblasts were transferred onto $2.5 \times 10 \mathrm{~cm}$ rectangular silicon dishes coated with $0.05 \%$ type I collagen (Koken, Tokyo, Japan) and were cultured in DMEM with $10 \%$ FBS for $24 \mathrm{~h}$. The subconfluent cells were then washed twice with PBS and the culture medium was replaced with DMEM containing $0.5 \%$ FBS. The chambers were mounted on a stretching stage that was driven by a computer controlled motor (Sigma Koki, Tokyo, Japan). Uniaxial cyclic stretch was applied on cells at 10 cycles/min with $10 \%$ length stretch for $24 \mathrm{~h}$.

\section{RNA isolation and RT-PCR}

Total cellular RNA was isolated from fibroblasts after dissolving in TRIzol reagent (Gibco BRL, NY) according to the manufactur-

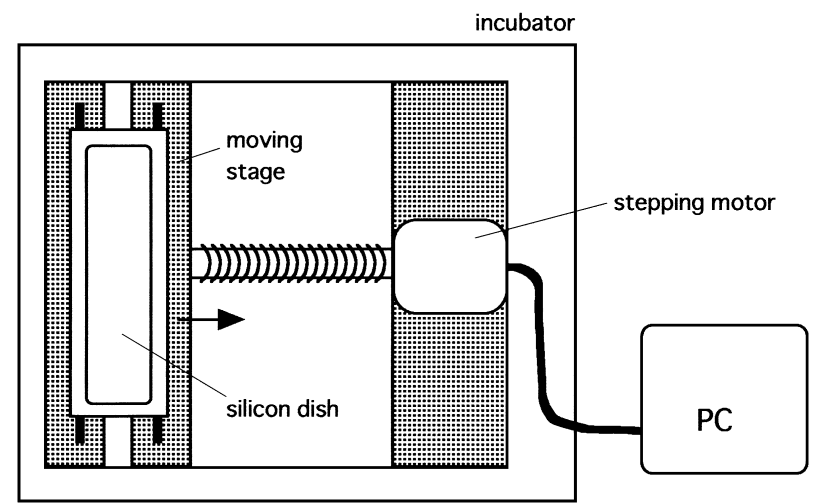

Fig. 1. The stretch system. Rectangular silicon dishes were held at one side by a fixed stage and the opposite side by a moving stage that was driven by a computer controlled motor.

er's instruction. The first strand cDNA was prepared from the RNA with reverse transcriptase (RTase) (M-MLV reverse transcriptase: Gibco BRL, Grand Island, NY). The cDNA was amplified by polymerase chain reaction (PCR) (Takara Z-taq: Takara Shuzo Co., Ltd., Shiga, Japan) using primers. The cyclic program was $94^{\circ} \mathrm{C}$ for $30 \mathrm{~s}, 60^{\circ} \mathrm{C}$ for $30 \mathrm{~s}, 72^{\circ} \mathrm{C}$ for $60 \mathrm{~s}$ and 20 $\mathrm{min}$ in the last cycle and comprised 22 cycles. The cycle number was selected so that all primers fell in the linear part of the curve and not toward the plateau region. Glyceraldehyde-3-phosphate dehydrogenase (GAPDH) was used as an internal control. Primers were derived from GenBank (http://www.ncbi.nih.gov) sequences and were designed by GeneWorks sequence analysis software (IntelliGenetics, Inc., Mountain View, CA). Primers specific for type I collagen $(\alpha 1(\mathrm{I})$ chain) (sense: 5'-CCAGCAGATCGAGAACATCC-3'; antisense: 5'-ATCGACAGTGACGCTGTAGG3'), type III collagen (sense: 5'-AACGGTCTCAGTGGAGAACG3'; antisense: 5'-CCACTCTTGAGTTCAGGATGG-3') and GAPDH(sense: 5'-AACAGCCTCAAGATCATCAGC-3'; antisense: 5'GGATGATGTTCTGGAGAGCC-3') were used and resulted in amplified products of 523, 869 and 199 bp, respectively. Densitometric analysis was performed using NIH imaging after resolving on $2 \%$ agarose gel stained with ethidium bromide. The resulting data were expressed as a ratio to the control value denoted as one.

\section{Enzyme-linked immunosorbent assay (ELISA) for TGF $-\beta 1$ protein}

TGF- $\beta 1$ in the cell culture supernate after $24 \mathrm{~h}$ cyclic stretch stimulation was measured by ELISA (R\&D Systems, Minneapolis, $\mathrm{MN})$. This assay employs the quantitative sandwich enzyme immunoassay technique. The cell culture supernate $(0.5 \mathrm{ml})$ was mixed with $0.1 \mathrm{ml}$ of $1 \mathrm{~N} \mathrm{HCl}$, incubated at room temperature for $10 \mathrm{~min}$, and neutralized by $1.2 \mathrm{~N} \mathrm{NaOH}$ and $0.5 \mathrm{M}$ HEPES. TGF$\beta 1$ protein was measured by ELISA using polyclonal antibody (R\&D Systems, Minneapolis, MN).

\section{Bioassay of TGF- $\beta 1$}

The relationship between TGF- $\beta 1$ and mRNA expression of col- 
lagen was investigated. Ligament fibroblasts were cultured in DMEM with $10 \%$ FBS. When the cultured cells became confluent, the culture medium was removed and the cells were washed with PBS. The culture medium was replaced with DMEM containing $0.5 \%$ FBS and treated with recombinant human TGF- $\beta 1$ (WAKO, Osaka, Japan) at a final concentration of 200 or $1000 \mathrm{pg} / \mathrm{ml}$. The cells were cultured for $24 \mathrm{~h}$ and the mRNA expression was evaluated.

The activation of TGF- $\beta 1$ in the culture medium was estimated by bioassay. The ligament fibroblasts were placed on tissue culture plates in DMEM with 10\% FBS for $24 \mathrm{~h}$. The cells were washed with PBS and further incubated for $24 \mathrm{~h}$ with the conditioned medium which had been collected from either culture chambers of 24 h, $10 \%$ stretched or non-stretched cells. Then, mRNA expression of the type I and III collagen was examined by RT-PCR.

\section{Effect of neutralizing antibody}

Anti-TGF- $\beta 1$ antibody (R\&D Systems, Minneapolis, MN) was used to determine if mechanical stretch-induced mRNA expression of collagen by ligament fibroblasts was mediated by TGF- $\beta 1$. The stretch experiments were repeated in the presence and absence of a neutralizing antibody. The ligament fibroblasts were stretched with anti-TGF- $\beta 1$ antibody (100 ng/ml) (Tsang et al., 1995) or equal amounts of a control antibody (IgY).

\section{Statistical analysis}

Student's $t$ test was used for statistical analysis. P values less than 0.05 were considered to indicate statistical significance.

\section{Results}

\section{Effects of stretch on cell alignment and proliferation}

The ligament fibroblasts did not align microscopically in response to the axial strain for $24 \mathrm{~h}$ (data not shown). There were no significant differences in the cell numbers counted with a hemocytometer between control and stretched fibroblasts. The ratio of stretched fibroblasts to control was $1.03 \pm 0.06$ (mean \pm SEM).

\section{Effect of stretch on collagen mRNA expression}

Fig. 2 shows RT-PCR analysis of type I and type III collagen mRNA according to mechanical stretch. The results indicated that the mRNA expression of type I and type III collagen was increased by the cyclic stretch. The ratios of stretch to control values of type I and type III collagen were $1.63 \pm 0.21$ and $2.69 \pm 0.39$, respectively.

\section{Effect of stretch on TGF- $\beta 1$ protein}

TGF- $\beta 1$ has been shown to induce collagen synthesis (Kresse and Schonherr, 2001). Since the mRNA expression of type I and type III collagen was increased by the cyclic stretch, TGF- $\beta 1$ secretion after the stretch was investigated.
A

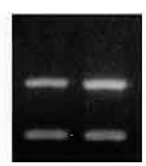

$(-)(+)$

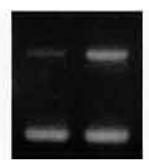

$(-)(+)$
B

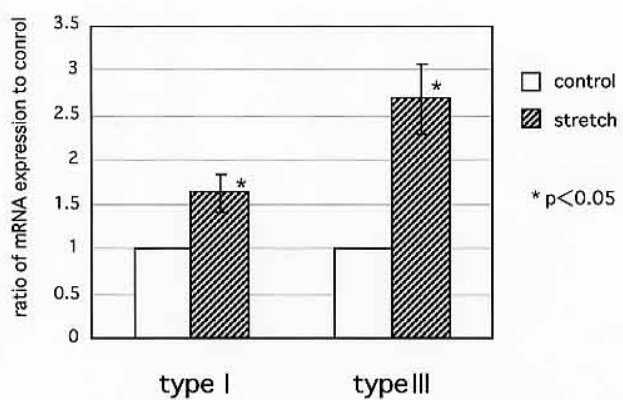

Fig. 2. (A) RT-PCR of type I and type III collagen mRNA in response to mechanical stretch. Integrated density values for polymerase products were normalized to the values for GAPDH. (B) The resulting data were then expressed and illustrated as a ratio of the control. Each bar represents mean \pm standard error of the mean (SEM) $(n=7)$. The mRNA expression of type I and type III collagen was increased by the cyclic stretch. ${ }^{*} \mathrm{p}<0.05$.

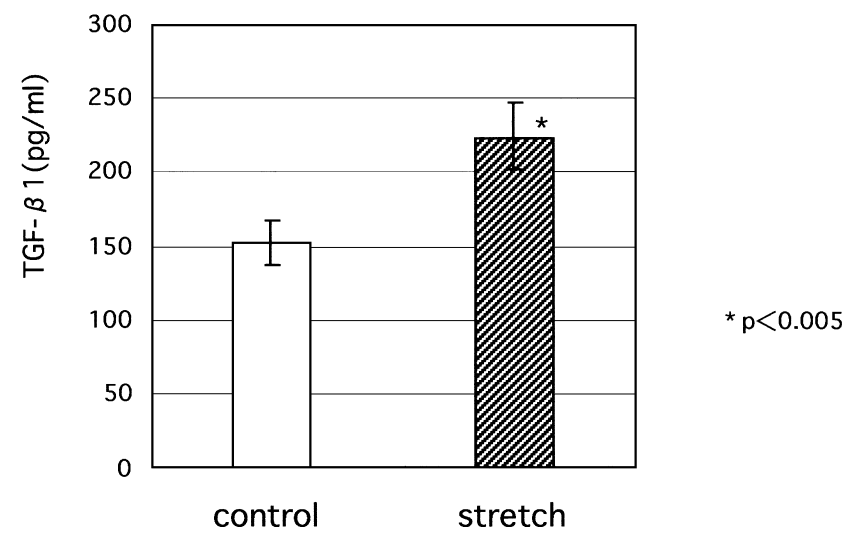

Fig. 3. Effect of stretch on the TGF- $\beta 1$ protein in the supernate. TGF- $\beta 1$ was increased by the stretch. TGF- $\beta 1$ protein was assayed by ELISA. Nonstretched cultures served as controls $(n=7$, mean \pm SEM). $* \mathrm{p}<0.005$.

TGF- $\beta 1$ protein in the cell culture supernate was shown in Fig. 3. It was found that TGF- $\beta 1$ protein in response to the stretch was increased to $149 \pm 11 \%$.

\section{Effect of TGF- $\beta 1$ on collagen mRNA expression}

To determine if TGF- $\beta 1$ induces mRNA expression of type I and type III collagen in ligament fibroblasts, the effect of TGF- $\beta 1$ on collagen mRNA expression was investigated. Fig. 4 shows that the mRNA expression of type I and type III collagen in ligament fibroblasts was increased in the presence of exogenous TGF- $\beta 1$ with a dose-dependent manner. The ratios of mRNA of type I and type III collagen to control were $1.23 \pm 0.01$ and $1.99 \pm 0.31$ at a concentration of 


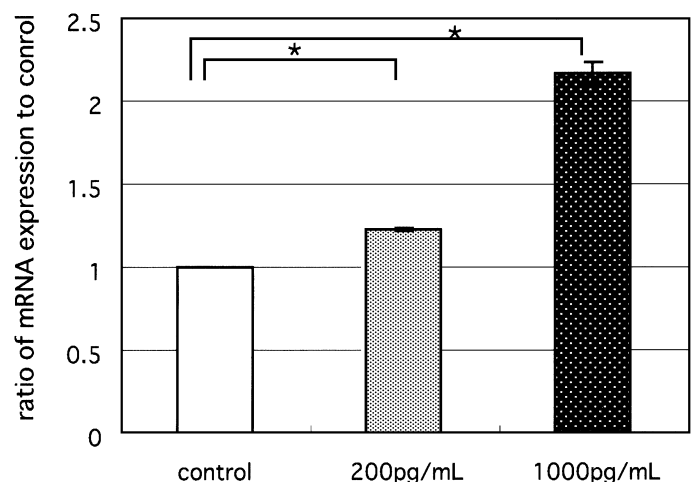

type I collagen

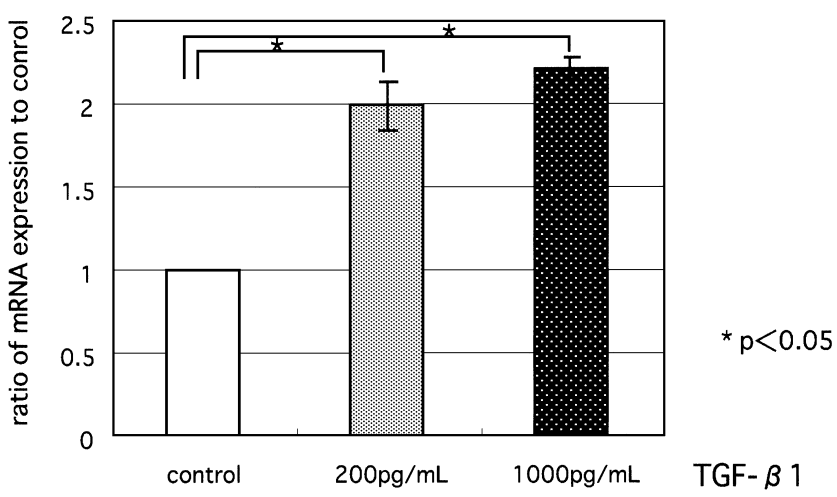

type III collagen

Fig. 4. TGF- $\beta 1$ increased type I and type III collagen mRNA expression by ligament fibroblasts. The mRNA content was assayed by RT-PCR ( $=3$, mean \pm SEM). $* \mathrm{p}<0.05$.

$200 \mathrm{pg} / \mathrm{ml}$, and $2.17 \pm 0.06$ and $2.22 \pm 0.14$ at $1000 \mathrm{pg} / \mathrm{ml}$, respectively.

\section{Bioassay by the conditioned medium}

The bioassay by the conditioned medium was performed in order to evaluate whether stretch-induced TGF- $\beta 1$ is active form. Differences of mRNA expression of the type I and type III collagen between control medium from nonstretched cells and conditioned one from stretched cells were shown in Fig. 5. The results indicated that the mRNA expression of the type I and type III collagen in the conditioned medium from stretched cells was increased in compared with that of control medium.

\section{Effect of anti-TGF- $\beta 1$ antibody}

To determine whether the stretch-induced mRNA expression of type I and type III collagen is dependent on TGF- $\beta 1$,

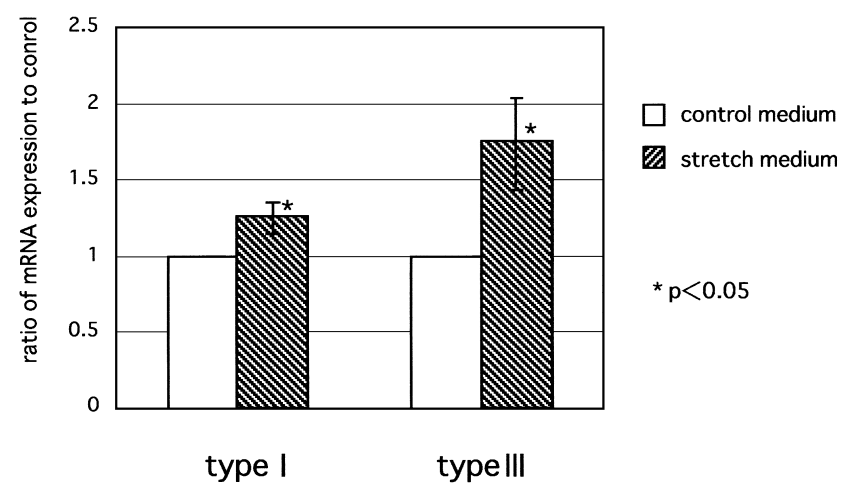

Fig. 5. Differences of mRNA expression of type I and type III collagen between control medium and stretch medium. The conditioned medium from stretched cells increased the mRNA expression. The mRNA content was assayed by RT-PCR ( $\mathrm{n}=4$, mean \pm SEM). ${ }^{*} \mathrm{p}<0.05$. the TGF- $\beta 1$ neutralizing antibody was added before the stretch. Effects of anti-TGF- $\beta 1$ antibody on the stretch-induced mRNA expression of type I and type III collagen were shown in Fig. 6. It was found that the stretch-induced mRNA expression of type I and type III collagen was markedly inhibited in the presence of anti-TGF- $\beta 1$ antibody whereas that of type I and type III collagen was increased by the stretch with IgY as a control.

\section{Discussion}

In the process of ligament healing, the synthesis of type I and type III collagen is stimulated by certain growth factors (Murphy et al., 1994). Although a small amount of type I collagen is produced, most of the newly synthesized collagen is type III in the early phase of healing (Woo et al.,

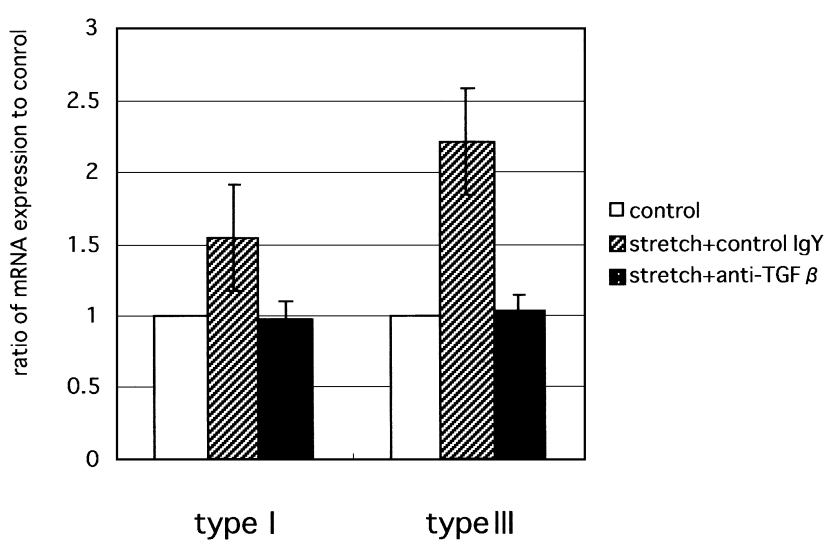

Fig. 6. Effect of anti-TGF- $\beta 1$ antibody on the stretch-induced mRNA expression of type I and type III collagen. In the presence of neutralizing anti-TGF- $\beta 1$ antibody, stretch-induced up-regulation of collagen mRNA expression was ablated. The mRNA content was assayed by RT-PCR ( $n=3$, mean \pm SEM). 
1999). The type III collagen is also increased in a remodeling process termed "ligamentization" after tendon graft (Amiel et al., 1986). In our study, the mRNA expression of type III collagen was higher than that of type I. This result suggests that mechanical stretch of the ligament fibroblasts is a positive regulator in the healing and remodeling process.

The effect of equibiaxial strain on ligament fibroblasts was investigated (Hsieh et al., 2000). The cells on a flexible circular membrane were stretched hemispherically by vacuum. ACL fibroblasts responded to cyclic strain by mRNA expression of higher levels of type I collagen with almost no significant increases in type III collagen. However, our study showed that mechanical stretch increased mRNA expression of both type I and type III collagen. Differences in the direction, duration, elongation rate and frequency of stretch may account for the inconsistency between them. Stretch direction may be especially important for the investigation of stretch response because the directions of mechanical loading are different among cell types in vivo. In order to mimic the physiological condition when ligament cells are stretched uniaxially, the system, which can apply uniaxial stretch to the cells in vitro, was developed in this study.

The alignments of a number of different type cells in response to cyclic surface deformation have been investigated (Naruse et al., 1998; Neidlinger-Wilke et al., 2001; Kato et al., 1998). Skin fibroblasts and osteoblasts become oriented in response to axial strain. The cell orientation in response to cyclic culture dish deformation is primarily due to avoidance of large axial surface strains and is specific to the cell type. In our experiment, the ligament cells did not align in response to the stretch, thus ligament cells may be hard to align by such stretch. Because cells were stretched in subconfluent density in this study, the alignment might be affected by cell-cell contact.

TGF- $\beta 1$ is a multifunctional cytokine that has been shown to induce new matrix synthesis (Kresse and Schonherr, 2001). Intracellular signaling by TGF- $\beta 1$ occurs via serine/threonine kinase receptors. Smad 2 and $\mathrm{Smad} 3$ are direct substrates of TGF- $\beta$ kinase and interact with Smad4. Smad complexes then translocate from the cytoplasm into the nucleus and stimulate collagen transcription (Ghosh et al., 2001). Several investigators have demonstrated that TGF- $\beta 1$ increases the collagen synthesis by ligament fibroblasts in vitro (DesRosiers et al., 1996; Marui et al., 1997). We showed that exogenous TGF- $\beta 1$ increased type I and type III collagen mRNA expression. The results of this study support previous investigators. Up-regulation of TGF$\beta 1$ by mechanical stretch was observed in other cell types, including smooth muscle cells, cardiac fibroblasts and mesangial cells (Li et al., 1998; Lee et al., 1999; O'Callaghan and Williams, 2000; Gruden et al., 2000). In ligament fibroblasts, we showed that cyclic stretch increased TGF- $\beta 1$ protein in the cell culture supernate.
Although some studies have shown increased extracellular matrix synthesis in response to stretch loading (Li et al., 1998; Lee et al., 1999; O'Callaghan and Williams, 2000), the signal pathway of mechanical stress remains unclear. This study showed that neutralizing anti-TGF- $\beta 1$ antibody ablated stretch-induced up-regulation of collagen mRNA expression. This result suggests that TGF- $\beta 1$ up-regulated by mechanical stretch stimulates gene expression of type I and type III collagen. Naruse et al. (1998) demonstrated that stretch-activated calcium influx through stretch-activated (SA) channels was essential in the molecular mechanism of converting physical forces to biochemical signals. Fluid-induced shear stress increased intracellular calcium concentration in ligament fibroblast (Gruden et al., 2000). In human mesangial cells, stretch activates, via a protein kinase C-dependent mechanism, p38 mitogen-activated protein (MAP) kinase, which independently induces TGF- $\beta 1$ (Hung et al., 1997). Schwachtgen et al. (1998) demonstrated that treatment of human endothelial cells with PD98059, a MAP kinase kinase inhibitor, inhibited shear stress activation of early growth response-1 (egr-1). However, Yamamoto et al. (1999) reported that neither PD98059 nor SB203580, a MAP kinase inhibitor, inhibited the effect of mechanical stretch on tenascin-C mRNA expression in rat cardiac myocytes.

TGF- $\beta 1$ is one of the most important regulators in the healing and remodeling process of the ligament. The temporal and spatial expression of TGF- $\beta 1$ in the healing rat patellar ligament was investigated by immunohistochemistry (Natsu-ume et al., 1997). It was shown that wounding provoked a rapid rise in TGF- $\beta 1$ levels at the site of patellar ligament injury which persisted for at least 8 weeks. There was an expression of TGF- $\beta 1$ at the adjacent uninjured site for 4 weeks. This result suggests that TGF- $\beta 1$ is an important cytokine over the whole length of ligament tissue in the healing process. Localization of growth factors in the reconstructed ACL was examined in the canine model (Kuroda et $a l ., 2000)$. In the reconstructed graft, stained levels for TGF- $\beta 1$ were increased in early postoperative period. In our study, mechanical stretch increased production of TGF- $\beta 1$, which stimulated mRNA expression of type I and type III collagen. Temporal regulation of mechanical stretch to ligament fibroblasts in vivo and in vitro, which can be a controlled release system of autocrine TGF- $\beta 1$, will allow design of novel strategies for graft surgery and tissue engineering.

\section{References}

AbiEzzi, S.S., Foulk, R.A., Harwood, F.L., Akeson, W.H., and Amiel, D. 1997. Decrease in fibronectin occurs coincident with the increased expression of its integrin receptor alpha5beta1 in stress-deprived ligaments. Iowa Orthop. J., 17: 102-109.

Amiel, D., Frank, C., Harwood, F., Fronek, J., and Akeson, W. 1984. Tendons and ligaments: a morphological and biochemical comparison. J. Orthop. Res., 1: 257-265. 
Amiel, D., Kleiner, J.B., Roux, R.D., Harwood, F.L., and Akeson, W.H. 1986. The phenomenon of "ligamentization": anterior cruciate ligament reconstruction with autogenous patellar tendon. J. Orthop. Res., 4: 162172.

Amis, A.A. and Dawkins, G.P. 1991. Functional anatomy of the anterior cruciate ligament. Fibre bundle actions related to ligament replacements and injuries. J. Bone Joint Surg. Br., 73B: 260-267.

Bessette, G.C. and Hunter, R.E. 1990. The anterior cruciate ligament. Orthopedics, 13: 551-562.

DesRosiers, E.A., Yahia, L., and Rivard, C.H. 1996. Proliferative and matrix synthesis response of canine anterior cruciate ligament fibroblasts submitted to combined growth factors. J. Orthop. Res., 14: 200-208.

Ghosh, A.K., Yuan, W., Mori, Y., Chen, S-j., and Varga, J. 2001. Antagonistic regulation of type I collagen gene expression by interferon-gamma and transforming growth factor-beta. Integration at the level of p300/ CBP transcriptional coactivators. J. Biol. Chem., 276: 11041-11048.

Girgis, F.G., Marshall, J.L., and Monajem, A. 1975. The cruciate ligament of the knee joint. Anatomical, functional and experimental analysis. Clin. Orthop., 106: 216-231.

Gruden, G., Zonca, S., Hayward, A., Thomas, S., Maestrini, S., Gnudi, L., and Viberti, G.C. 2000. Mechanical stretch-induced fibronectin and transforming growth factor-beta1 production in human mesangial cells is p38 mitogen-activated protein kinase-dependent. Diabetes, 49: 655661 .

Harwood, F.L. and Amiel, D. 1992. Differential metabolic responses of periarticular ligaments and tendon to joint immobilization. J. Appl. Physiol., 72: 1687-1691.

Hsieh, A.H., Tsai, C.M., Ma, Q.J., Lin, T., Banes, A.J., Villarreal, F.J., Akeson, W.H., and Sung, K.L. 2000. Time-dependent increases in typeIII collagen gene expression in medical collateral ligament fibroblasts under cyclic strains. J. Orthop. Res., 18: 220-227.

Hung, C.T., Allen, F.D., Pollack, S.R., Attia, E.T., Hannafin, J.A., and Torzilli, P.A. 1997. Intracellular calcium response of ACL and MCL ligament fibroblasts to fluid-induced shear stress. Cell. Signal., 9: 587594.

Kato, T., Ishiguro, N., Iwata, H., Kojima, T., Ito, T., and Naruse, K. 1998. Up-regulation of COX2 expression by uni-axial cyclic stretch in human lung fibroblast cells. Biochem. Biophys. Res. Commun., 244: 615-619.

Kresse, H. and Schonherr, E. 2001. Proteoglycans of the extracellular matrix and growth control. J. Cell Physiol., 189: 266-274.

Kuroda, R., Kurosaka, M., Yoshiya, S., and Mizuno, K. 2000. Localization of growth factors in the reconstructed anterior cruciate ligament: immunohistological study in dogs. Knee Surg. Sports Traumatol. Arthrosc., 8: 120-126.

Lee, A.A., Delhaas, T., McCulloch, A.D., and Villarreal, F.J. 1999. Differential responses of adult cardiac fibroblasts to in vitro biaxial strain patterns. J. Mol. Cell. Cardiol., 31: 1833-1843.

Lee, J., Harwood, F.L., Akeson, W.H., and Amiel, D. 1998. Growth factor expression in healing rabbit medial collateral and anterior cruciate ligaments. Iowa Orthop. J., 18: 19-25.

Li, Q., Muragaki, Y., Hatamura, I., Ueno, H., and Ooshima, A. 1998. Stretch-induced collagen synthesis in cultured smooth muscle cells from rabbit aortic media and a possible involvement of angiotensin II and transforming growth factor-beta. J. Vasc. Res., 35: 93-103.

Marui, T., Niyibizi. C., Georgescu, H.I., Cao, M., Kavalkovich, K.W., Levine, R.E., and Woo, S.L. 1997. Effect of growth factors on matrix synthesis by ligament fibroblasts. J. Orthop. Res., 15: 18-23.

Miyazono, K., and Heldin, C.H. 1992. Structure, function and possible clinical application of transforming growth factor-beta. J. Dermatol., 19: 644-647.

Murphy, P.G., Loitz, B.J., Frank, C.B., and Hart, D.A. 1994. Influence of exogenous growth factors on the synthesis and secretion of collagen types I and III by explants of normal and healing rabbit ligaments. Biochem. Cell Biol., 72: 403-409.

Nagineni, C.N., Amiel, D., Green, M.H., Berchuck, M., and Akeson, W.H. 1992. Characterization of the intrinsic properties of the anterior cruciate and medial collateral ligament cells: an in vitro cell culture study. $J$. Orthop. Res., 10: 465-475.

Naruse, K., Yamada, T., and Sokabe, M. 1998. Involvement of SA channels in orienting response of cultured endothelial cells to cyclic stretch. Am. J. Physiol., 274: 1532-1538.

Natsu-ume, T., Nakamura, N., Shino, K., Toritsuka, Y., Horibe, S., and Ochi, T. 1997. Temporal and spatial expression of transforming growth factor-beta in the healing patellar ligament of the rat. J. Orthop. Res., 15: 837-843.

Neidlinger-Wilke, C., Grood, E.S., Wang, J.H-C., Brand, R.A., and Claes, L. 2001. Cell alignment is induced by cyclic changes in cell length: studies of cells grown in cyclically stretched substrates. J. Orthop. Res., 19: $286-293$.

O'Callaghan, C.J. and Williams, B. 2000. Mechanical strain-induced extracellular matrix production by human vascular smooth muscle cells: role of TGF-beta(1). Hypertension, 36: 319-324.

Schwachtgen, J.L., Houston, P., Campbell, C., Sukhatme, V., and Braddock, M. 1998. Fluid shear stress activation of egr-1 transcription in cultured human endothelial and epithelial cells is mediated via the extracellular signal-related kinase $1 / 2$ mitogen-activated protein kinase pathway. J. Clin. Invest., 101: 2540-2549.

Tohyama, H., and Yasuda, K. 1998. Significance of graft tension in anterior cruciate ligament reconstruction. Basic background and clinical outcome. Knee Surg. Sports Traumatol. Arthrosc., 6: 30-37.

Tsang, M.L., Zhou, L., Zheng, B.L., Wenker, J., Fransen, G., Humphrey, J., Smith, J.M., O'Connor-McCourt, M., Lucas, R., and Weatherbee, J.A. 1995. Characterization of recombinant soluble human transforming growth factor-beta receptor type II (rhTGF-beta sRII). Cytokine, 7: 389397.

Woo, S.L., Hildebrand, K., Watanabe, N., Fenwick, J.A., Papageorgiou, C.D., and Wang, J.H. 1999. Tissue engineering of ligament and tendon healing. Clin. Orthop., 367: 321-323.

Yamamoto, K., Dang, Q.N., Kennedy, S.P., Osathanondh, R., Kelly, R.A., and Lee, R.T. 1999. Induction of tenascin-C in cardiac myocytes by mechanical deformation. Role of reactive oxygen species. J. Biol. Chem., 274: $21840-21846$.

(Received for publication, March 4, 2002

and in revised form, April 15, 2002) 